\title{
MICROEMPREENDEDOR INDIVIDUAL (MEI): UMA ANÁLISE DO PERFIL NO MUNICÍPIO DE PARANAGUÁ/PR (2010-2017)
}

\author{
Maria Cristina Izidro Spagnollo ${ }^{1}$ \\ Ivan Jairo Junckes ${ }^{2}$
}

RESUMO: O artigo explora o quantitativo de optantes pelo microempreendedor individual para conhecer e discutir minimamente os sujeitos na sua formalização. Para o desenvolvimento desta investigação, foi realizado um levantamento do perfil do MEI nos últimos oito anos (2010 - 2017), no município de Paranaguá, considerando as seguintes características: sexo, faixa etária e CNAE. Após um levantamento teórico, foi possível notar uma escassez nos trabalhos realizados Microempreendedor no Litoral do Paraná e a inexistência de um artigo desenvolvido especialmente para este município. Neste contexto para o desenvolvimento deste trabalho, foi realizada uma pesquisa bibliográfica e uma análise quantitativa com base nos dados extraídos do Portal do Empreendedor. Os resultados demonstram que o perfil do microempreendedor é composto em sua maioria por mulheres, na faixa etária entre 31 e 40 anos se concentrando principalmente em atividades de comércio/confecção de vestuário e/ou acessórios. O perfil do MEI em Paranaguá aponta para a necessidade de um reforço nas políticas públicas dirigidas à capacitação das mulheres no mercado de serviços.

Palavras-chave: MEl. Microempreendedor Individual. Políticas Públicas. Empreendedorismo. Paranaguá.

1 E-mail: ma_spagnollo@hotmail.com

2 E-mail: ivanjj@ufpr.br 


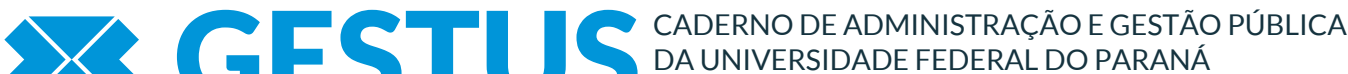 SETOR LITORAL}

\section{INTRODUÇÃO}

A legislação que regulamenta o microempreendedor individual (MEI) objetiva proporcionar aos trabalhadores e trabalhadoras a formalização facilitada de sua ocupação laboral, ou seja, a retirada da informalidade de uma maneira menos burocrática. Para que isso ocorra foi promulgada em 19 de dezembro de 2008 a Lei Complementar $n^{\circ} 128$, destinada explicitamente para o MEI. A Lei estabelece em seu Art. $4^{\circ}$ que os microempreendedores podem se formalizar de forma simplificada ${ }^{\text {. }}$

Com a formalização os empreendedores garantem benefícios, como: o registro no cadastro nacional de pessoas jurídicas (CNPJ), o registro na previdência social, a disponibilidade de serviços bancários exclusivos para empresas, isenção de tributos federais e isenção de taxas para o registro e finalização da empresa. Todavia, o empreendedor deve exercer uma atividade que se enquadre no campo de atuação destinado ao $\mathrm{MEI}$, e conter um faturamento anual inferior à $\mathrm{R} \$ 81$ mil conforme disposto na LCP n 155 de 27 de outubro de 2016 em seu Art. 18A $\$ 1^{\circ}$.

Devido à grande facilidade e os vários benefícios adquiridos pela formalização, em novembro de 2018 estavam registrados 7.579.658 trabalhadores como MEl em todo o Brasil, contudo são raras as pesquisas acadêmicas que demonstram o perfil desses empreendedores. O propósito deste estudo é realizar um levantamento do perfil desses microempreendedores individuais em um município especificamente.

A investigação teve como campo de pesquisa o Município de Paranaguá, onde foram levantados dados através do portal do empreendedor tomando como base o período 2010-2017. A pergunta de partida para a pesquisa foi: Qual o perfil do MEI no município de Paranaguá? Considerando-se basicamente sexo, idade e classificação de atividade econômica. O objetivo do trabalho é explorar o quantitativo de optantes pelo microempreendedor individual para conhecer e discutir minimamente os sujeitos na sua formalização. Utilizou-se como metodologia uma pesquisa bibliográfica e análise quantitativa, com base principalmente nos dados disponibilizados em sites oficiais de acordo com a Lei do Empreendedor, dentro do período estipulado pela pesquisa.

O presente texto está dividido em três partes. Na primeira seção é apresentada a base teórica, abordando os temas, conceitos e histórico do MEI no Brasil, além de uma abordagem das políticas voltadas a este grupo laboral. Na segunda parte demonstra-se os resultados obtidos através de dados secundários e o perfil do MEI

1 Uma relação completa da legislação MEl pode ser obtida no Portal do Empreendedor através do link http://www.portaldoempreendedor.gov.br/legislacao 


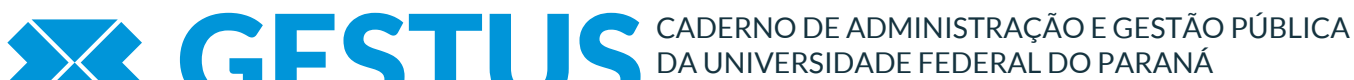 \\ SETOR LITORAL}

no município de Paranaguá. Por último, são tecidas breves considerações finais a respeito do trabalho realizado.

\section{EMPREENDEDORISMO: CONCEITOS E HISTÓRICO NO BRASIL}

O termo empreendedorismo está associado ao conceito de inovação, como é exposto por um de seus precursores, o economista Joseph Schumpeter. 0 mesmo afirma que esse processo de inovação consiste em novas criações a partir dos recursos já existentes. Segundo Schumpeter (1949) existem características que um empreendedor deve compreender, as quais ele denominou de "capacidade empresarial distinta", algumas delas são: ter aptidão para administração, entender e saber tirar proveito das situações e, por fim, saber tomar decisões que auxiliem no crescimento. O empreendedorismo é "aquele que destrói a ordem econômica existente pela introdução de novos produtos e serviços, pela criação de novas formas de organização ou pela exploração de novos recursos e materiais" (SCHUMPETER, 1949). Tendo como sua perspectiva mais ampla que "[...] é utilizado para designar os estudos relativos ao empreendedor, seu perfil, suas origens, seu sistema de atividades, seu universo de atuação" (DOLABELA, 2003, p. 43).

A inovação está interligada diretamente ao conceito de empreendedorismo. Neste contexto, inovar pode ser um dos aspectos mais difíceis com relação ao empreender, tendo em vista que lançar um produto e/ou serviço é complicado levando em consideração todas as tecnologias e métodos de informação existentes.

Entrepreneurship (Empreededorismo) é usado na linguagem acadêmica e empresarial como administração empreendedora, que envolve aspectos culturais, psicológicos, econômico e tecnológico. O espírito empreendedor está relacionado com a satisfação de alguma necessidade. O empreendedor está sempre em busca de mudança, reagindo a ela aproveitando como sendo uma oportunidade. Ele convive com os riscos e incertezas que envolvem as decisões. Ele é inovador na concretização de ideias e transformador de oportunidades.

No Brasil, o empreendedorismo só passou a ser incentivado sistematicamente e a contar com apoios governamentais a partir de 1990, após a criação de entidades como o Serviço Brasileiro de Apoio às Micro e Pequenas Empresas (SEBRAE) e a Sociedade Brasileira para Exportação de Software (SOFTEX), segundo Dornelas (2005). Estando sempre pronta e preparada para as mudanças e inovações é importante que a administração pública seja receptiva ao empreendedorismo. Incentivando as novas práticas que possam trazer bons resultados, que aumentem o 


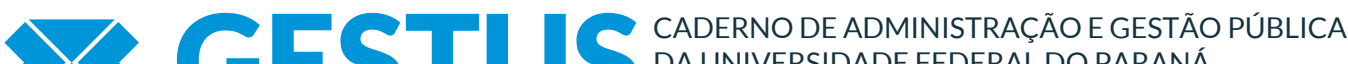 DA UNIVERSIDADE FEDERAL DO PARANÁ SETOR LITORAL}

mercado empresarial bem como suas potencialidades.

Podendo destacar o SEBRAE (http://www.sebrae.com.br/sites/PortalSebrae) como um dos principais serviços de apoio, sendo uma entidade privada e sem fins lucrativos. Atuando no suporte no território brasileiro para os microempreendedores e empresas de médio e pequeno porte, sempre com o intuito de incentivar o desenvolvimento econômicos destas. A entidade oferta cursos de qualificação, seminários e consultorias tanto para os empreendedores como para os gestores públicos que atuam nas salas do empreendedor, dentro das prefeituras. Além de conter uma assessoria telefônica para todos os cidadãos.

Diante das perspectivas de políticas de apoio, um programa de pesquisa mede a evolução do empreendedorismo no Brasil em relação a outros países, denominado GEM (Global Entrepreneurship Monitor). O GEM presenta duas definições para o empreendedorismo, a primeira como oportunidade:

O empreendedorismo de oportunidade, onde o empreendedor visionário sabe aonde quer chegar, cria uma empresa com planejamento prévio, tem em mente o crescimento que quer buscar para a empresa e visa a geração de lucros, empregos e riquezas. (DORNELAS, 2005, p.28).

E a segunda como necessidade:

O empreendedorismo de necessidade, em que o candidato a empreendedor se aventura na jornada empreendedora mais por falta de opção, por estar desempregado e não ter alternativas de trabalho. (DORNELAS, 2005, p.28).

Com base neste conceito, o GEM constata em sua última pesquisa que o Brasil estava em oitavo lugar no ranking de empreendedorismo entre 31 países com o desenvolvimento econômico no ano de 2016, com 26 milhões de brasileiros envolvidos em alguma atividade empreendedora.

Neste contexto teórico, é necessário incluir uma perspectiva com relação a informalidade e a formalidade. A informalidade consiste em um trabalho não regulamentado e em sua maioria de atividades desenvolvidas no âmbito familiar, ou em atividades comerciais ambulantes (LIMA, 2010).

Podemos destacar, que o mercado informal é constituído por pessoas que apresentam dificuldades de reemprego, de ingresso no mercado de trabalho, ou que por opção querem uma renda através de formas de trabalho por conta própria 


\section{GESTUS S SETOR LITORAL}

(CACCIAMALI, 1983). Os trabalhadores informais, por não serem resguardados por leis trabalhistas ou regulamentações, acabam tendo como característica um alto índice de vulnerabilidade (FEIJÓ, 2010).

Alguns fatores que que influenciam na informalidade são: (1) fiscalização frágil por parte do governo, (2) possibilidade de proporcionar preços baixos, (3) não pagamento de impostos, custos trabalhistas e regulatórios, e (4) o baixo índice de despesas correspondente a custos contábeis (PAES, 2010). Contudo, existem algumas desvantagens em ser um empreendedor informal, sendo: (1) pagamentos e punições por violar a lei, (2) dificuldade na área judiciaria, (3) problemas no acesso à linha de credito e (4) a inviabilidade de participação no sistema previdenciário (FILÁRTIGA, 2007).

É complexo analisar a situação da informalidade, pois ela depende muito das escolhas de cada sujeito no mercado de trabalho, principalmente quando ele é correlacionado com a renda deste trabalho, ressaltando que geralmente um empreendedor informal inicia com um investimento no negócio baixo. É importante mencionar que o princípio do empreendedorismo com relação a inovação é o mesmo para o empreendedor informal e formal, todavia os fatores que levam ao indivíduo se formalizar os diferenciam.

Com relação ao sexo feminino no empreendedorismo, é notável que ao longo dos anos a participação feminina no mercado de trabalho vem evoluindo. Todavia esta inserção depende de diversos fatores, alguns sendo por exemplo, características pessoais e familiares e demanda do mercado. É necessário levar em consideração o posicionamento da família, principalmente quando existe a presença de crianças, conforme expõe a Fundação Carlos Chagas (2007).

Neste sentido, para Lindo et al. (2007), a participação de mulheres casadas e com filhos no mercado de trabalho está cada vez maior, mesmo que seu cônjuge esteja ou não empregado. Devido a todos esses fatores, as mulheres estão atuando de forma expressiva em negócios, em movimentos sociais ou na política. De acordo com Wikens (1989), as mulheres estão empreendendo cada vez mais, as mesmas largam empregos seguros para assumirem o risco de novos negócios, mais rápido que o sexo masculino. Conforme a pesquisa elaborada pelo GEM (2016), as mulheres correspondem a $51 \%$ dos empreendedores no ano de 2016 no Brasil, dado que as mulheres investem mais em capacitação, procuram melhores informações e tendem a criar empresas sólidas e lucrativas.

Em relação a outros países, grande parte apresenta uma supremacia masculina, com exceção apenas do Brasil e México que são equilibrados, conforme a 
tabela 01 demonstrada abaixo:

Tabela 01 - Taxas específicas de empreendedorismo inicial segundo gênero - países selecionados - 2016

\begin{tabular}{cccc}
\hline Países & Masculino & Feminino & TEA \\
\hline Brasil & 19,2 & 19,9 & 19,6 \\
\hline África do Sul & 8,0 & 5,9 & 6,9 \\
\hline Alemanha & 6,0 & 3,1 & 4,6 \\
\hline China & 11,8 & 8,6 & 10,3 \\
\hline Estados Unidos & 14,8 & 10,5 & 12,6 \\
\hline Índia & 13,5 & 7,6 & 10,6 \\
\hline México & 9,3 & 10,0 & 9,6 \\
\hline Rússia & 6,9 & 5,7 & 6,3 \\
\hline
\end{tabular}

Fonte: GEM 2016 - Percentual de empreendedores iniciais de cada classe.

Após este breve apanhado com relação aos conceitos do empreendedorismo, abordaremos no próximo tópico as políticas públicas voltadas ao MEl e suas realidades.

\section{MICROEMPREENDEDOR INDIVIDUAL: POLÍTICAS E REALIDADES}

As políticas públicas são desenvolvidas com o intuito de resolver um fato ou problema, buscando atender a interesses conflitantes na sociedade. Visando auxiliar e conceder apoio às micro e pequenas empresas instituiu-se no Brasil uma política pública focada neste grupo, a Lei 9.317, de 5 de dezembro de 1996, foi a primeira tentativa para atender aos interesses das pequenas empresas regulamentando 0 sistema tributário e instituindo um sistema integrado de pagamento de impostos e contribuições, denominado de Simples.

A Lei 9.317 foi substituída pela Lei Geral de Micro e Pequenas Empresas - Lei complementar $n^{\circ} 123 / 2006$, que instituiu o Estatuto da Microempresa, e estabeleceu normas para enquadramento fiscal das Microempresas (ME) e Empresas de Pequeno Porte (EPP). Dois anos mais tarde, foi sancionada também a Lei do Microempreendedor Individual - Lei Complementar n 128/2008, que instituiu um novo modelo de pessoa 


\section{GESTUS S SETOR LITORAL}

jurídica, tendo como objetivo possibilitar que os trabalhadores informais possam se formalizar perante o mercado de trabalho.

A Lei do Microempreendedor Individual foi elaborada para legalizar os milhares de trabalhadores autônomos que geram receita e não eram assegurados por alguns benefícios essenciais e serem inseridos de maneira formal no mercado de trabalho. Importante salientar que através do MEI foi possível que trabalhadores informais conquistassem benefícios que antes só eram destinados aos trabalhadores inseridos no mercado formal. Dentre esses benefícios podemos destacar: formalização digital e simplificada, isenção de impostos federais; contribuição social e emissão de nota fiscal eletrônica.

Com relação imposto recolhido por meio do Documento de Arrecadação do Simples Nacional Microempreendedor Individual - DASMEI, independente de sua arrecadação o valor será fixo, desde que a mesma não ultrapasse o valor anual de oitenta mil reais. A arrecadação é utilizada para proporcionar os benefícios correspondentes a previdência, como: auxílio-doença, aposentadoria por invalidez (ambos benefícios previdenciários exigem 12 contribuições mensais); aposentadoria por idade (exige 180 contribuições mensais); salário-maternidade (exige 10 contribuições mensais); e pensão por morte e auxílio-reclusão (exigível a partir do primeiro pagamento).

O MEI ainda tem a possibilidade de realizar a contração de um funcionário, desde que o mesmo receba um salário-mínimo ou o piso da categoria, não podendo possuir mais de um estabelecimento e nem sendo participante ou proprietário de outra empresa.

Ocorreu mais uma importante alteração para esse setor, sendo a Lei Complementar 147 (LC 147) de 2014, a qual ajustou o MEI para uma política pública de inclusão. A LC 147 instituiu que o MEl é uma política pública com o objetivo realizar a formalização de empreendedores e a inclusão social e previdenciário na condição, ou modalidade, de microempresa (Art. 18-E). Além das referidas mudanças, a legislação também garante que o microempreendedor individual tenha os mesmos direitos assegurados à Microempresa - ME e à Empresa de Pequeno Porte - EPP, nas áreas trabalhistas, de licitação, de acesso ao crédito, entre outros.

Com relação ao acesso no mercado, a LC 147 modifica e complementa a Lei Complementar 123, e estabelece que nas contratações públicas por meio de licitação, seja concedido ao microempreendedor um tratamento diferenciado e de forma simples, com o intuito de promover a economia municipal, regional, a ampliação da eficiência de políticas públicas e um incentivo a inovação e a tecnologia (Art. 47). Cabe destacar ainda o Art. 48 da LC 123 modificado pela LC 147: 


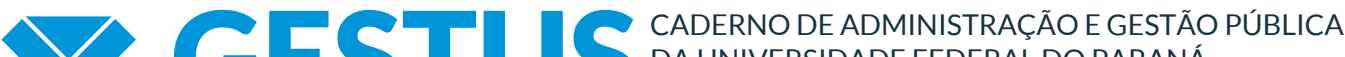 DA UNIVERSIDADE FEDERAL DO PARANÁ SETOR LITORAL
}

\begin{abstract}
"Art. 48. Para o cumprimento do disposto no art. 47 desta Lei Complementar, a administração pública:

I - deverá realizar processo licitatório destinado exclusivamente à participação de microempresas e empresas de pequeno porte nos itens de contratação cujo valor seja de até $\mathrm{R} \$ 80.000,00$ (oitenta mil reais);

II - poderá, em relação aos processos licitatórios destinados à aquisição de obras e serviços, exigir dos licitantes a subcontratação de microempresa ou empresa de pequeno porte;

III - deverá estabelecer, em certames para aquisição de bens de natureza divisível, cota de até $25 \%$ (vinte e cinco por cento) do objeto para a contratação de microempresas e empresas de pequeno porte.
\end{abstract}

Além destas condições, também cabe incluir nesta discussão o acesso ao mercado externo, possibilitado ao MEI de uma maneira simplificada através da LC 147/14, que dispõe:

Art. 49-A. A microempresa e a empresa de pequeno porte beneficiárias do SIMPLES usufruirão de regime de exportação que contemplará procedimentos simplificados de habilitação, licenciamento, despacho aduaneiro e câmbio, na forma do regulamento.

Parágrafo único. As pessoas jurídicas prestadoras de serviço de logística internacional quando contratadas por beneficiários do SIMPLES estão autorizadas a realizar atividades relativas a licenciamento administrativo, despacho aduaneiro, consolidação e desconsolidação de carga, bem como a contratação de seguro, câmbio, transporte e armazenagem de mercadorias, objeto da prestação do serviço, na forma do regulamento.

Seguindo esse avanços, foi concedido ao MEl, através da Lei Complementar $n^{\circ} 155$ de 27 de outubro de 2016, a possibilidade de aumentar sua renda bruta anual para oitenta e um mil reais, mantendo o benefício sobre o recolhimento do imposto único (Art. 18-A $\S 1^{\circ}$ ). Além de proporcionar a realização da baixa de sua empresa via portal eletrônico (Art. 18-A § 16-A ).

Através destes benefícios, foi possível ampliar o acesso aos microempreendedores individuais, de formas que a Federação Nacional das Empresas de Serviços Contábeis e das Empresas de Assessoramento, Perícias, Informações e Pesquisas (FENACON, 2018) afirma que os MEl foram responsáveis pela abertura de $78,4 \%$ nos negócios abertos em 2018 , ou seja, o mesmo está conquistando destaque na área dos novos negócios. 


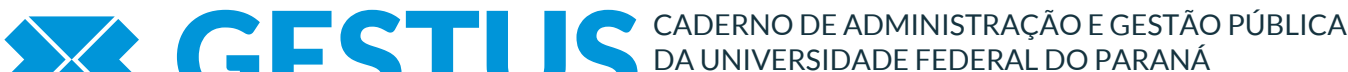 SETOR LITORAL}

\section{MATERIAIS E MÉTODOS}

Para o desenvolvimento deste trabalho primeiramente foi realizado um levantamento teórico dos principais temas, sendo: Empreendedorismo: conceito e histórico no Brasil e o Microempreendedor Individual: políticas públicas e realidades. Para a coleta de dados foi utilizado como base o Portal do Empreendedor (www. portaldoempreendedor.me/). No espaço destinado a estatísticas conseguimos localizar os seguintes tópicos: faixa etária, sexo e CNAE. Com base nas estatísticas encontradas no portal, foi realizado uma seleção dos dados correspondentes ao município de Paranaguá, para confecção dos gráficos utilizando um programa de planilhas e posteriormente selecionado o Estado do Paraná para realização de um comparativo. Para realização de uma análise e comparativo, utilizamos dados dispostos pelo Global Entrepreneurship Monitor, Pesquisa Econômica Aplicada (IPEA), Instituto Brasileiro de Geográfica e Estatísticas (IBGE).

\section{RESULTADOS}

A Lei do Microempreendedor Individual teve sua homologação em 19 de dezembro de 2008, sendo definido que a partir do dia 01 de julho de 2009 já seria possível realizar a inscrição como pessoa jurídica na categoria de MEI. Entretanto houve um tempo para a implantação, como por exemplo: a estruturação das Salas do Empreendedor, as quais são utilizadas justamente para realizar o atendimento e esclarecimento de dúvidas, e a implantação do Portal do Empreendedor, onde possibilita o cadastro, estatísticas, qualificação de colaboradores, entre outros. Em consequência deste fato, não houve nenhuma formalização no município de Paranaguá no de 2009, todavia no primeiro ano de registro, 2010, foram realizadas 4.332 inscrições. Conforme demonstrado no gráfico 01, podemos observar a evolução das inscrições no microempreendedor individual no período de 2010 a 2017, tendo acumulado no final do ano de 2017, 10.813 inscritos. Em dezembro de 2017 constavam ativos $5.598 \mathrm{MEls.}$ 


\section{Z GESTUS SETOR LITORAL}

Gráfico 1 - Evolução do Microempreendedor individual em Paranaguá/PR (2010 a 2017)

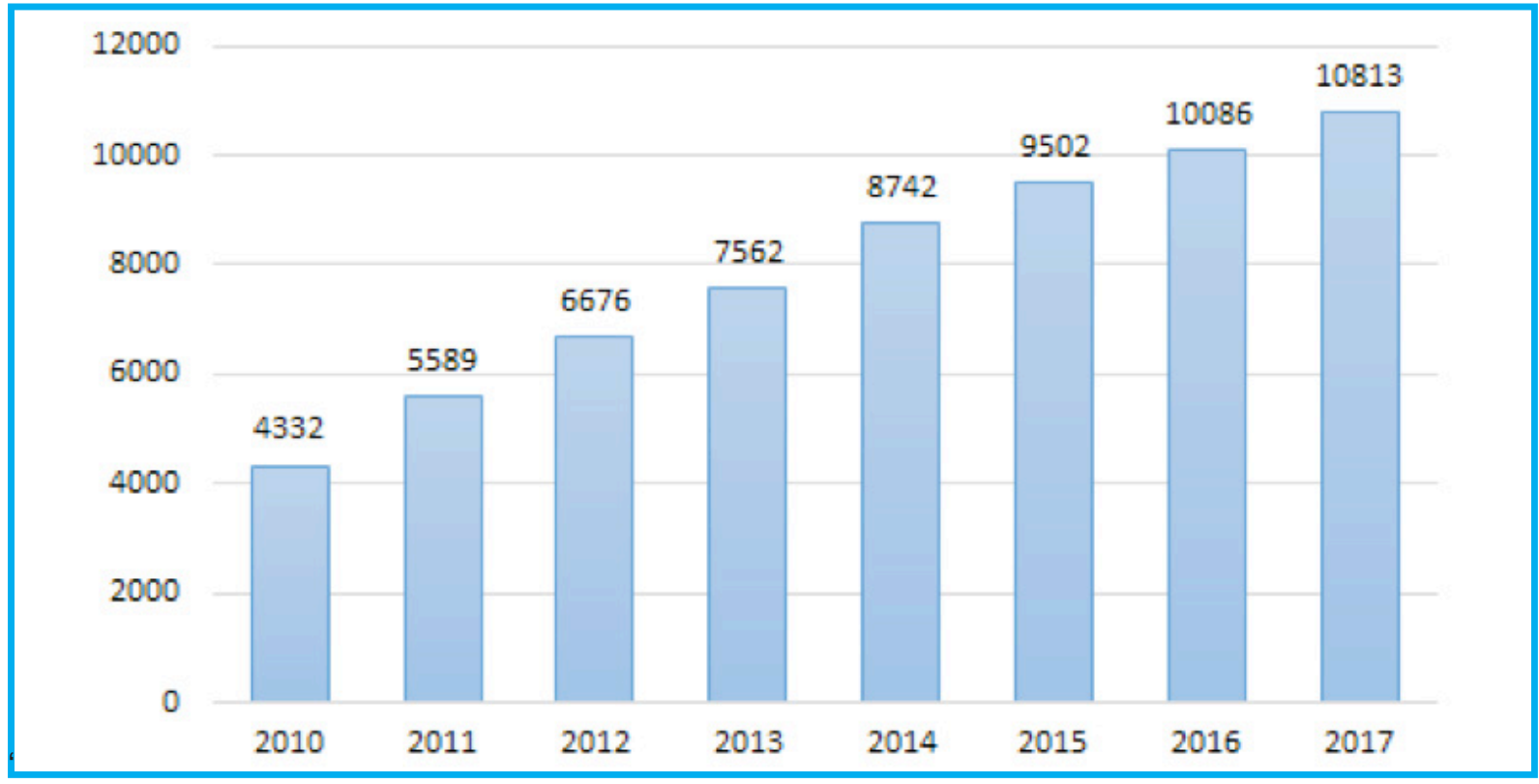

Fonte: Portal do Empreendedor - www.portaldoempreendedor.gov.br/estatisticas. Elaboração própria

De acordo com o gráfico 02, podemos verificar que no período de 2010 a 2017, houve uma média de 925 inscritos, notando que houve um ápice no ano de 2011 seguindo de um declínio de $46 \%$ em 2016, retornando a elevar os índices de forma branda no próximo ano. Neste quantitativo não levamos em consideração o ano de 2010, devido ser um valor atípico.

Gráfico 2 - Formalizações anuais no município de Paranaguá/PR (2011 a 2017)

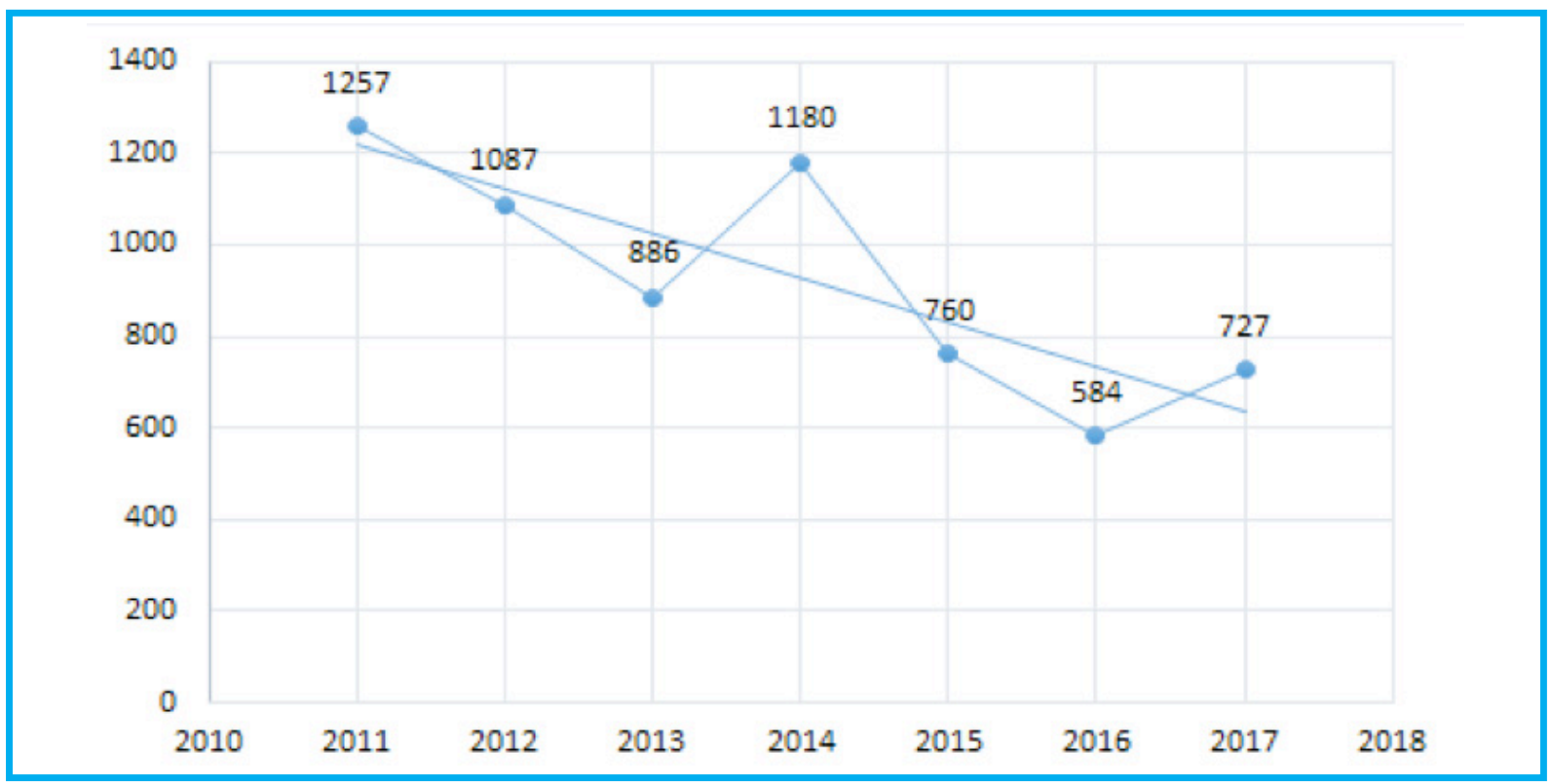

Fonte: Portal do Empreendedor - www.portaldoempreendedor.gov.br/estatisticas. Elaboração própria 


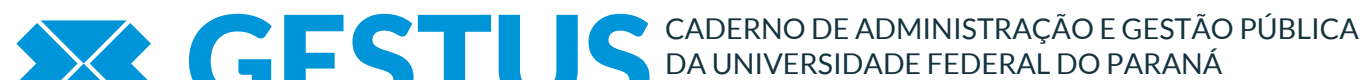 SETOR LITORAL}

Vistos os quantitativos das inscrições anuais, passamos a explorar algumas características do microempreendedor individual no município, sendo elas sexo, faixa etária e classificação de atividade econômica (CNAE).

No contexto da característica de sexo no período de 2010 a 2017 é possível identificar que no município de Paranaguá a relação é equilibrada, mesmo que as mulheres ocupem $53,5 \%$ deste espaço, conforme disposto no gráfico 3 , isso pode ser explicado pelas principais atividades entre os CNAE's utilizados no município, que será demonstrado posteriormente.

\section{Gráfico 3 - MEI por sexo em Paranaguá/PR (2010 a 2017)}

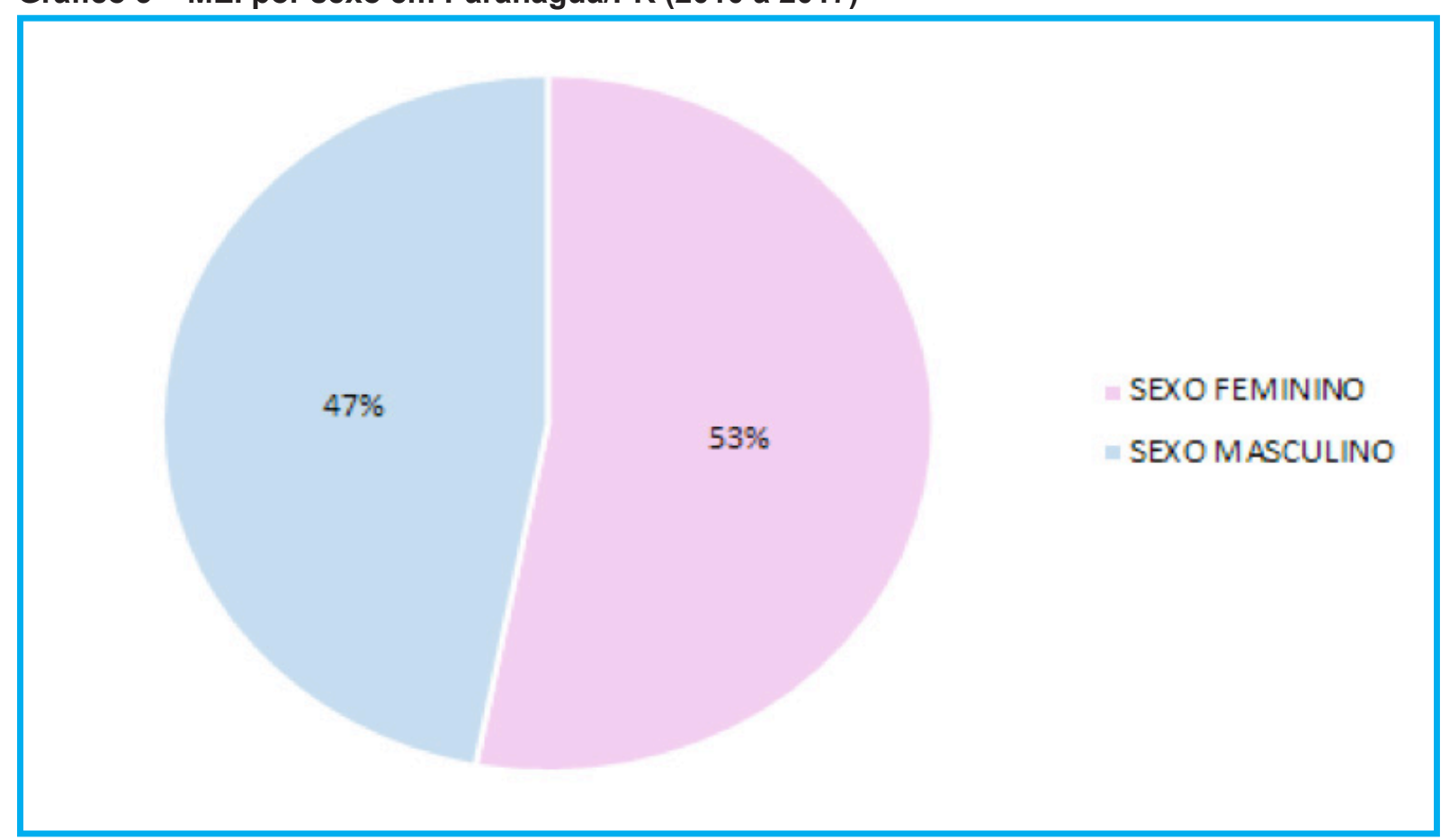

Fonte: Portal do Empreendedor - www.portaldoempreendedor.gov.br/estatisticas. Elaboração própria

No tocante a idade dos MEI, Paranaguá apresenta durante os anos de 2010 a 2017, 30\% dos microempreendedores individuais na faixa etária de 31 a 40 anos, seguido de $24 \%$ na faixa de 41 a 50 anos e $22 \%$ entre os 21 a 30 anos, nestas três faixas etárias podem ser consideradas as principais, de acordo com o gráfico 4 . Isso pode ocorrer devido aos indivíduos de idade superior estarem em grande parte estabilizados e/ou já terem idade para solicitar o benefício da aposentadoria e os mais novos estarem assalariados ou participando de programas de estágio e jovem aprendiz. 


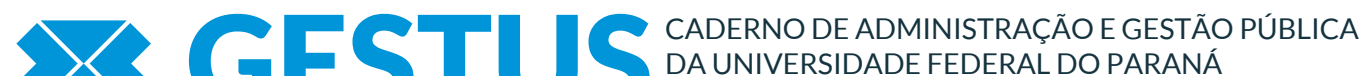 SETOR LITORAL}

\section{Gráfico 4 - Distribuição do MEl por faixa etária em Paranaguá (2010 a 2017)}

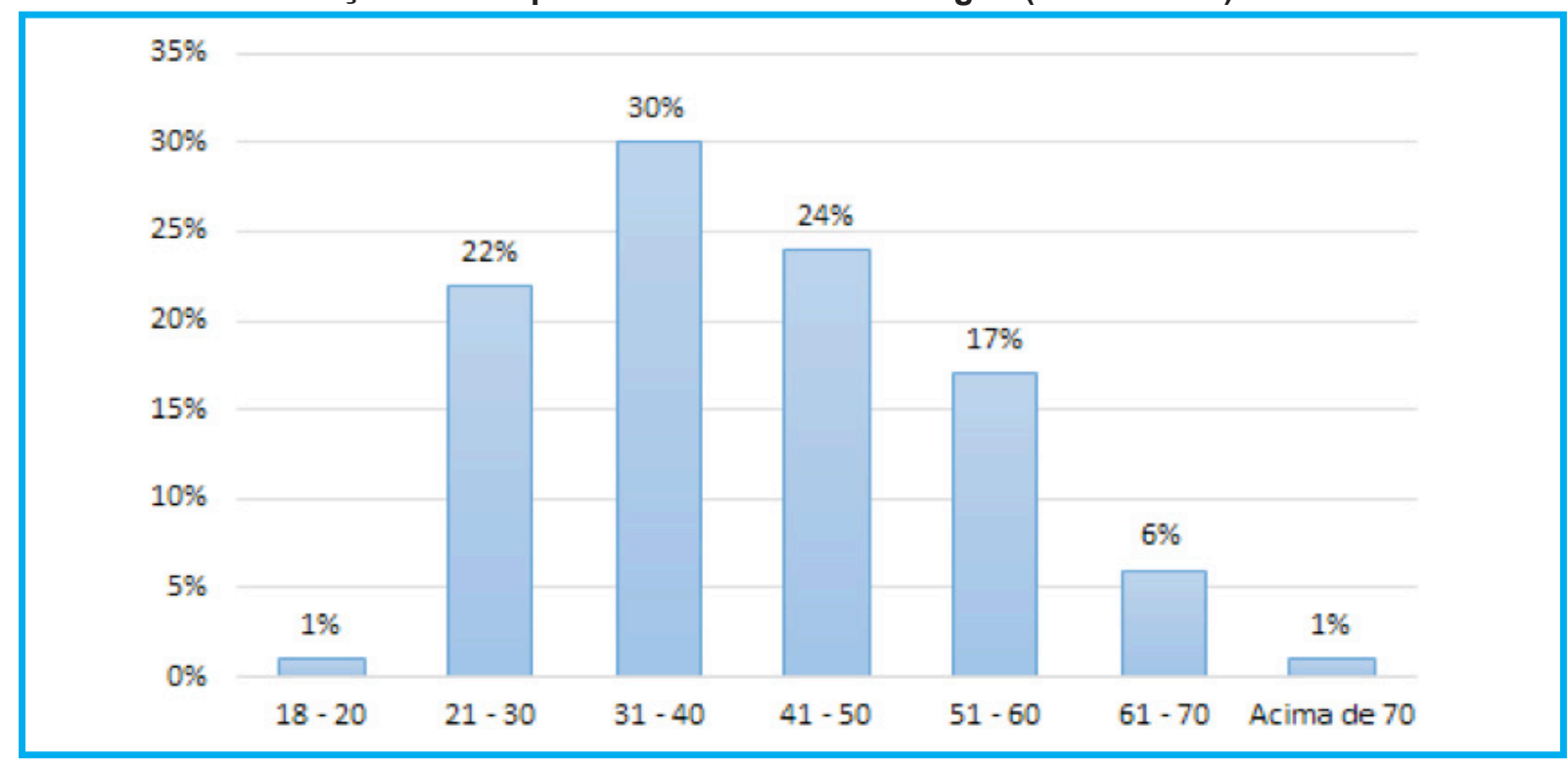

Fonte: Portal do Empreendedor - www.portaldoempreendedor.gov.br/estatisticas. Elaboração própria

O microempreendedor individual tem em sua legislação a listagem específica de Classificação Nacional de Atividades Econômicas (CNAE) em que se enquadram. Para explorar esses dados, utilizamos no período de 2010 a 2017 os indivíduos ativos, relacionamos as atividades econômicas que concentram $60 \%$ dos optantes pelo microempreendedor individual, podendo ser consideradas as principais atividades no município, conforme tabela 2. As maiores concentrações em determinadas classes pode ser explicada por atividades de baixo custo inicial e também que não necessitam de instruções elevadas por parte dos optantes.

Tabela 02 - Relação das principais atividades dentro do CNAE utilizadas em Paranaguá (2010-2017)

\begin{tabular}{lc}
\hline \multicolumn{1}{c}{ Descrição do CNAE agregado } & $\%$ agregado \\
\hline Restaurantes, bares, ambulantes de alimentação e similares & $17 \%$ \\
\hline Comércio varejista de artigos do vestuário, acessórios e confecção sob medida & $16 \%$ \\
\hline Cabeleireiros & $7 \%$ \\
\hline Obras de alvenaria & $7 \%$ \\
\hline Comércio varejista de mercadorias em geral, com predominância de produtos & $3 \%$ \\
\hline Serviços de lavagem e reparação mecânica de veículos automotores & $2 \%$ \\
\hline Transporte e serviços de entrega rápida & $2 \%$ \\
\hline Outros & $46 \%$
\end{tabular}

Fonte: Portal do Empreendedor - www.portaldoempreendedor.gov.br/estatisticas. Elaboração própria 


\section{Z GESTUS DA UNIVERSIDADE FEDERAL DO PARANÁ SETOR LITORAL}

Após o levantamento dos dados é possível realizar um perfil dos microempreendedores no município, sendo em sua maioria mulheres, na faixa etária entre 31 e 40 anos se concentrando principalmente em atividades de restaurantes, bares e ambulantes, e comércio/confecção de vestuário e/ou acessórios.

De acordo com o economista Joseph Schumpeter (1949) o empreendedorismo se trata da criação de inovações através de recursos existentes, todavia tal criação e inovação está condicionada pelas condições objetivas de sujeitos trabalhadores com limitadas condições para o exercício criativo da inovação, haja vista a predominância de serviços marginais na economia local. Todavia é importante destacar que além da pouca inovação e elevada adaptação um dos principais pontos com relação a adesão das mulheres é devido à necessidade, conforme demonstrado o conceito de Dornelas (2005), onde dispõe que a falta de opção é o grande ponto para a maior parte de adesão. A atualidade do município corresponde às características demonstradas pela Fundação Carlos Chagas (2007), onde expõe os motivos pelo qual as mulheres estão aderindo ao mercado de trabalho, sendo um dos principais a contribuição na renda familiar, e claro, também podemos ressaltar características pessoais. As mulheres tiveram que procurar outras formas de contribuir e/ou sustentar suas residências, sendo uma delas o mercado informal e posteriormente a formalidade através do microempreendedor individual.

Com relação a este panorama, podemos notar como a perspectiva da economista Maria Cacciamali (1983) se enquadra no município de Paranaguá, tendo em vista que a mesma reforça que o mercado informal é constituído por pessoas que apresentarem dificuldades de reemprego e de ingresso no mercado de trabalho. $E$ através destes fatores que o indivíduos que iniciam no mercado informal acabam optando pela formalização posteriormente por meio do microempreendedor individual. Outro fator a se observar é com relação a pesquisa desenvolvida pelo Global Entrepreneurship Monitor, onde afirma que o empreendedorismo no Brasil é composto por sua maioria de mulheres, semelhante ao município estudado, em que a maioria dos microempreendedores são mulheres.

Em comparação com o Estado do Paraná, Paranaguá apresenta números consideravelmente diversos com relação ao sexo dos optantes. De acordo com o Portal do Empreendedor, em todo o Estado se concentram 456.879 inscritos, sendo que destes $54 \%$ é do sexo masculino. Com relação à faixa etária é semelhante, sendo $30 \%$ indivíduos entre 31 à 40 anos.

Considerando a relação entre total de habitantes e optantes no MEI, Paranaguá apresenta uma relação bastante reduzida. No Estado do Paraná, os MEI representam 


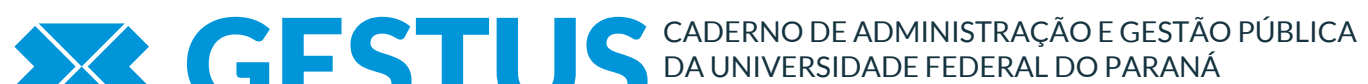 \\ SETOR LITORAL}

$4 \%$ da população, todavia no município apenas $4 \%$ da população que se tornou um microempreendedor. De acordo com o Instituto Brasileiro de Geografia e Estatística (IBGE), Paranaguá contava com 153.666 habitantes em 2017, sendo destes cerca de $53 \%$ deste estão na faixa etária entre 20 a 64 anos, ou seja, se enquadram na principal faixa etária disponível ao mercado de trabalho. Ainda sob os dados do IBGE, o mesmo informar que apenas $27,7 \%$ são ocupados, ou seja, possuem trabalho formal, os outros $25,3 \%$ provavelmente participam do mercado de trabalho informal. Com base nisto, temos um panorama desfavorável, tendo em vista que em um contexto geral, os optantes pelo $\mathrm{MEI}$ são apenas $1 \%$ do total de habitantes no município.

\section{CONSIDERAÇÕES FINAIS}

Em virtude do conteúdo abordado na presente pesquisa, podemos compreender que objetivo principal foi alcançado, sendo que o mesmo consistia em realizar uma análise do perfil do $\mathrm{MEI}$, contendo os seguintes aspectos: sexo, faixa etária e CNAE. Neste contexto, estabeleceu como perfil do MEl: mulheres, entre 30 a 41 anos, atuantes nas áreas de restaurantes, bares, ambulantes e comércios de vestuários e/ou acessórios.

Paranaguá apresenta um quadro quantitativo semelhante ao MEI no Brasil, conforme podemos demonstrar no comparativo com a pesquisa desenvolvida pelo GEM. A partir deste ponto também notamos, como boa parte do referencial teórico representa a situação do $\mathrm{MEI}$ em Paranaguá, principalmente no que diz respeito aos motivos para entrar em um negócio inicialmente informal e futuramente realizar a formalização a partir do MEl. Salientando-se que com o desenvolvimento deste trabalho foi possível dimensionar o quão importante é a política do MEI para a inserção adaptativa de trabalhadores e trabalhadoras no mercado de trabalho/serviços e geração de renda.

Ainda são inúmeros os pontos a serem abordados por estudos nessa área, alguns exemplos disso, são: percentual de desenvolvimento litoral do Paraná devido a implementação da política pública do MEl; comparação corresponde ao índice de formalização entre os municípios do litoral; e entre várias outras oportunidades. 


\section{Z GESTUS DA UNIVERSIDADE FEDERAL DO PARANÁ SETOR LITORAL}

\section{REFERÊNCIAS}

BRASIL. Lei Complementar $n^{\circ} 123$ de 14 de dezembro de 2006. Instituiu o Estatuto Nacional da Microempresa e da Empresa de Pequeno Porte. Site do Planalto. Disponível em: http://www.planalto. gov.br/ccivil_03/leis/lcp/lcp123.htm. Acesso em: 23 ago 2018

BRASIL. Lei Complementar n ${ }^{\circ} 128$ de 19 de dezembro de 2008. Altera a Lei Complementar no 123, de 14 de dezembro de 2006. Site do Planalto. Disponível em: http://www.planalto.gov.br/ccivil_03/LEIS/ LCP/Lcp128.htm. Acesso em: 28 ago 2018

BRASIL. Lei Complementar no 147 de 7 de agosto de 2014. Altera a Lei Complementar no 123, de 14 de dezembro de 2006. Site do Planalto. Disponível em: http://www.planalto.gov.br/ccivil_03/LEIS/LCP/ Lcp147.htm. Acesso em: 10 out 2018

BRASIL. Lei Complementar no 155 de 27 de outubro de 2016, Altera a Lei Complementar no 123, de 14 de dezembro de 2006, para reorganizar e simplificar a metodologia de apuração do imposto devido por optantes pelo Simples Nacional. Site do Planalto. Disponível em: http://www.planalto.gov.br/ccivil_03/ LEIS/LCP/Lcp155.htm. Acesso em: 15 out 2018

CACCIAMALI, M. C. O setor informal urbano e formas de participação na produção. São Paulo: Ed. IPE, 1983.

DOLABELA, Fernando. Oficina do empreendedor. 5 ed. São Paulo: Cultura, 2003.

DORNELAS, José Carlos Assis. Transformando ideias em negócios. 2.ed. Rio de Janeiro: Elsevier, 2005.

Federação Nacional das Empresas de Serviços Contábeis e das Empresas de Assessoramento, Perícias, Informações e Pesquisas. Disponível em: http://www.fenacon.org.br/noticias/mei-puxouabertura-de-empresas-no-primeiro-semestre-3638/. Acesso em: 26 nov. 2018

FEIJÓ, Carmem Aparecida. Quão heterogêneo é o setor informal brasileiro. In: Revista de economia contemporânea, Rio de Janeiro, V. 13, n. 2, p. 329-354, 2010.

FERREIRA, Ademir Antônio; REIS, Ana Carla Fonseca; PEREIRA, Maria Isabel. Gestão Empresarial de Taylor a nossos dias, Ed. pioneira, São Paulo, 2000.

FILÁRTIGA, G. B. Custos de transação, instituições e a cultura da informalidade no Brasil. Revista do BNDES, Rio de Janeiro: V. 14, N. 28, p. 121-144, 2007.

FUNDAÇÃO CARLOS CHAGAS. Mulheres, trabalho e família. Disponível em: https://www.fcc.org.br/ bdmulheres/serie2.php?area=series (2007). Acesso em: 01 nov. 2018

INSTITUTO BRASILEIRO DE GEOGRAFIA E ESTATÍSTICA. Disponivél em: https://cidades.ibge.gov. br/brasil/pr/paranagua/panorama. Acesso em: 23 nov. 2018.

LIMA, J. C. Participação, empreendedorismo e autogestão: uma nova cultura do trabalho? Sociologias, Ano 12, N. 25, 2010, p. 158-198

LINDO, M. R.; CARDOSO, P. M.; RODRIGUES, M. E.; WETZEL, U. Vida pessoal e vida profissional: os desafios de equilíbrio para mulheres empreendedoras do Rio de Janeiro. RAC-Eletrônica, v. 1, n. 1, p. $1-15,2007$.

PAES, N. L. Mudanças no sistema tributário e no mercado de crédito e seus efeitos sobre a informalidade no Brasil. Nova Economia, V. 20, N. 2, 2010, p. 315-340. 


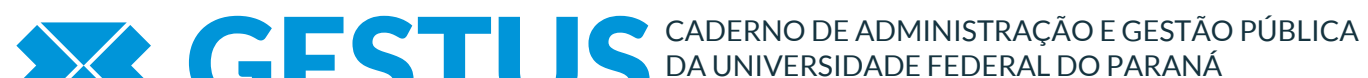 SETOR LITORAL}

PORTAL DO EMPREENDEDOR. MEI - Microempreendedor Individual. Disponivél em: http://www. portaldoempreendedor.gov.br/estatisticas. Acesso em: Acesso em: 25 set. 2018

SCHUMPETER, J. A. The Theory of Economic Development. Cambridge, Mass: Harvard University Press, 1949.

WILKENS, J. A Mulher Empreendedora. São Paulo: Mc-Graw-Hill, 1989. 